\title{
How do we survive and grow to support South African and African paediatrics in the future?
}

Over the past decade, the milieu in which the South African Journal of Child Health (SAJCH) finds itself operating has changed dramatically. The journal, which is now in its 12th year, is one of a number of specialist journals in the South African Medical Association (SAMA) stable published by its wholly owned publishing company, the Health and Medical Publishing Group. The journal has created a successful niche in supporting the publication of research by young and emerging researchers in the broad field of child health, particularly as it pertains to southern and sub-Saharan Africa. The journal particularly prides itself on supporting the publication of postgraduate research, such as that produced by registrars doing their MMed degrees for specialist registration in South Africa (SA) and other African regions. Its current acceptance rate is just over $50 \%$.

At the time of establishment of the journal, funding of specialist journals was heavily supported by advertising revenue from the pharmaceutical industry, which initially allowed the $S A J C H$ to produce four print issues per year. Although advertising revenue to the SAMA stable of journals has dwindled dramatically over the last two decades, which has necessitated online-only publication, it has been possible to continue to publish open-access issues without charging the authors an article processing or publication fee, through the continued financial support of and encouragement from the SAMA Board. This arrangement is no longer possible, as a result of of the continued escalation in costs. The HMPG Board has proposed the introduction of a publication fee to all its specialist journal editors. The fee is to be paid by the authors on the acceptance of their manuscript for publication by the journal. The details of the publication fee, and which articles and authors will attract it, have not yet been finalised, but as soon as they are, notification will be provided on the journal website.

Several suggestions related to the publication fee have been made, including that only articles attracting the Department of Higher Education and Training (DHET) subsidy will be charged, but that papers written by authors (first and/or senior) who are members of SAMA would have the fee partially or wholly waived, and that authors who have contributed substantially to the journal by reviewing articles for the $S A J C H$ could have the fee discounted. It must be emphasised that the introduction of a publication fee remains a proposal, and that the detail has not been finalised or agreed upon by all the editors involved; however, because of the likelihood that the publication fee will become a reality in the next few months, we felt it important that prospective authors be informed as soon as possible.

On the positive side, it should be pointed out that $S A J C H$ is accredited by the DHET for subsidy purposes, and that the journal is listed, rated, ranked and extracted by Scopus. Further, its openaccess status and full-text availability on the SciELO (Scientific Electronic Library Online) website (http://www.scielo.org/php/ index.php?lang=en) means that full-text articles are available to researchers anywhere in the world.

In closing, I would like to pay tribute to the mainly SA reviewers who continue to provide detailed, independent, blinded assessments of the manuscripts submitted for publication. Many reviewers go beyond the call of duty and provide very helpful and supportive comments and edits using track changes, which provide authors with useful insights into the editorial changes necessary to improve the quality of their manuscript. These reviews maintain and improve the overall quality of the journal and help to separate the $S A J C H$ from the profusion of predatory open-access journals that have flooded the online health journal space.

\section{John M Pettifor}

MB BCh, FCPaed (SA), PhD (Med), MASSAf

Editor

South African Journal of Child Health

john.pettifor@wits.ac.za

S Afr J Child Health 2018;12(2):42. DOI:10.7196/SAJCH.2018.v12i2.1578 